\title{
Hegemoni Fashion Barat Pada Busana Bangsawan di Bali Utara (1800-1940)
}

\author{
A.A. Ngr. Anom Mayun K. Tenaya \\ Program Studi Desain Fashion, Fakultas Seni dan Desain ISI Denpasar \\ Jl. Nusa Indah, Sumerta, Kec. Denpasar Timur, Kota Denpasar, Bali 80235-Indonesia
}

anomayun3@gmail.com

Penampilan busana bangsawan di puri-puri Bali Utara pada era 1800-1940 menunjukan adanya hegemoni budaya dalam berbusana terhadap sistem busana tradisional Bali, khususnya di Bali Utara. Pengaruh budaya asing, khususnya Barat terjadi melalui pertemuan langsung penduduk Bali Utara dengan pedagang dari Eropa. Kaum bangsawan Bali Utara yang berasal dari dua kerajaan besar, yakni Kerajaan Karangasem dan Buleleng menerima baik kedatangan bangsa Barat pada awalnya. Dua puri besar ini berusaha melakukan perubahan sosial kultural dengan bantuan pihak Barat yang kemudian berhasil menguasai Bali. Penelitian ini menggunakan metode kualitatif dengan pendekatan kajian budaya dan studi fashion untuk menjelaskan elemen-elemen fashion Barat pada busana bangsawan Bali Utara pada 1800-1940. Hasil penelitian menunjukkan bahwa pada busana kaum bangsawan pria terlihat elemen-elemen fashion Barat, terutama pada pemakaian baju dan kelengkapan busana, seperti: rompi, dasi, dan aksesoris, seperti: lencana, jam, pin, dan topi. Pada busana bangsawan wanita terlihat pada pemakaian baju kastim dan penggunaan motif aksesoris seperti bros, giwang, dan leontin, serta gelung yang menyerupai tiara pada kepala bangsawan wanita Eropa. Pengaruh budaya Barat dalam tatabusana bangsawan Bali Utara 1800-1940 terjadi melalui hegemoni fashion. Dengan pasti, gaya hidup bangsawan Bali Utara pada era 1800-1940 menjadi ke barat-baratan. Modus operandi hegemoni melalui pendidikan dan pemaksaan etika berbusana Barat terutama pada kaum wanita.

Kata kunci; hegemoni, fashion, barat, busana bangsawan, bali utara.

\section{Hegemony of West Fashion in Royal Attire in North Bali in 1800-1940}

The appearance of noble clothing in the palaces of North Bali in the 1800-1940 era showed the existence of cultural hegemony in dressing against the traditional Balinese dress system, especially in North Bali. The influence of foreign cultures, especially the West, occurred through direct encounters with North Bali residents and traders from Europe. The nobles of North Bali who came from two major kingdoms, i.e. the Kingdom of Karangasem and Buleleng welcomed the arrival of the West at first. These two kingdoms, the so-called puri, tried to make socio-cultural changes with the help of the West who later succeeded in controlling Bali. This study used a qualitative method with a cultural studies approach and fashion studies to unravel the elements of Western fashion in the royal attire in North Bali in 1800-1940. The results showed that in the male royal attires, elements of Western fashion were seen, especially in the jacket usage and its ornate apparels, such as: vests, ties, and accessories include medals, pocketwatch, pins, and hat. In the noblewomen's clothing, it can be seen in the use of velvet cloth and the use of motifs accessory such as brooches, earrings, and pendants, as well as headdress that resemble the tiara, the European noblewomen headdress. The influence of Western culture the nobility attire in North Bali 1800-1940 occurred through the hegemony of fashion. Without doubt, the lifestyle of the nobility of North Bali in the 1800-1940 era turned to the west. The modus operandi of hegemony is through education and the imposition of western dress ethics, especially on women.

Keywords: hegemony. Fashion, west, attire, noblemen, north bali.

Proses Review : 1 - 20 Mei 2021, Dinyatakan Lolos: 31 Mei 2021 


\section{PENDAHULUAN}

Latar belakang

Busana bagi bangsawan merupakan alat komunikasi sosial yang penting, yakni pernyataan status khusus (privilege) dalam masyarakat. Terkait busana yang dikenakan oleh anggota keluarga istana, ada tanda-tanda budaya yang harus dibaca, seperti: bahan baku, motif, gaya busana, dan perlengkapan busana (Soedibyo, 2003). Tandatanda tersebut berbicara tentang kualitas-kualitas terbaik, seperti: kemuliaan, kewibawaan, kekayaan, dan kekuatan. Citra yang dihadirkan oleh busana yang digunakan bangsawan Bali Utara pada 1800-1940 melalui desain, material, dan motif merupakan hasil kreativitas dari dalam istana. Dengan kemampuan artistik yang mendarah daging dalam masyarakat Bali terutama di lingkungan istana atau puri, bangsawan Bali Utara menunjukkan gaya berbusana tersendiri. Karakteristik busana bangsawan Bali Utara 1800-1940 menampilkan kombinasi nilai-nilai tradisional yang masih kuat dipegang dengan budaya asing sebagai bukti pergaulan internasional bangsawan Bali Utara.

Penelitian ini menunjukkan dan sekaligus mendiskusikan elemen-elemen asing dalam busana yang dikenakan bangsawan di Bali Utara. Untuk mengembangkan kajian tentang busana bangsawan Bali Utara beberapa tulisan menjadi acuan, antara lain tulisan Arini Arumsari, Agus Sachari, dan Andryanto Rikrik Kusmara (2019) yang memaparkan nilai nilai tradisional menjadi dasar perkembangan fashion di Bali. Dalam penelitian lain, Langi dkk (2017), menyimpulkan bahwa sistem sosial di Bali, tekstil, dan busana saling berhubungan dan saling mendukung dalam sebuah ekosistem tradisi Bali. Tulisan Nakatani (2020) merupakan pendekatan fashion Barat terhadap kain-kain tradisional, termasuk kain ikat Bali. Taylor (2002) menyebutkan peran ideologi fashion (hegemony, subcultures, and pleasures) sebagai kenderaan penyebaran ideologi. Penelitian ini menjelaskan bagaimana Barat mempengaruhi busana bangsawan di Bali Utara.

Tujuan Penelitian.

Busana bangsawan Bali Utara pada era 1800-1940 mengalami percampuran elemen-elemen asing yang membentuk karateristik tersendiri. Proses percampuran tersebut dapat terjadi melalui berbagai cara, salah satunya melalui hegemoni budaya asing, khususnya Barat. Oleh karena itu, penelitian ini bertujuan membuktikan adanya hegemoni fashion Barat terhadap busana bangsawan di Bali Utara.

\section{Teori Yang Digunakan.}

Penelitian ini menggunakan teori Hegemoni Kultural yang digagas oleh Antonio Gramsci. Melalui teori ini dijelaskan kebudayaan sebagai alat dominasi. Teori hegemoni menyatakan bahwa kesepakatan berjalan karena adanya kesatuan moral dan intelektual. Menurut Patria (2003), supremasi sebuah kelompok mewujudkan diri dalam dua cara, sebagai dominasi dan sebagai kepemimpinan intelektual dan moral. Menurut Gramsci penguasa mempergunakan cara lewat dominasi atau penindasan dalam bentuk kekuatan (force) dan hegemoni yakni memegang kendali kepemimpinan intelektual dan moral yang diterima secara sukarela lewat kesadaran (Bellah, 1996). Teori hegemoni kultural akan menjelaskan adanya hegemoni fashion Barat terhadap busana bangsawan di Bali Utara.

\section{METODE PENELITIAN}

Penelitian seni dan budaya, termasuk studi fashion merupakan penelitian kualitatif. Fokus penelitian mencakup pendekatan intepretatif terhadap subjek kajian dan sekumpulan data empiris, seperti teks dan gambar atau visual. Analisis data diuraikan secara deskripsi yakni penjelasan secara naratif.

Sumber data dalam penelitian ini adalah teks tertulis dan non tertulis. Data berupa teks tertulis diperoleh dalam berbagai literatur, seperti: buku referensi tentang kain, busana, dan aksesoris, buku-buku tentang koleksi museum, artikel, dan berbagai tulisan di internet. Data non teks antara lain busana, aksesoris, dan data visual, seperti: foto dan gambar.

\section{ANALISIS DAN INTEPRETASI DATA}

Pada masa lalu, bangsawan di Bali Utara adalah orangorang yang suka bersolek dan sadar berpenampilan, suka akan kerapian; termasuk merapikan rambut dengan menggunakan malam, dan berhias dengan busana yang elegan serta aksesoris yang indah. Melalui busana citra terbaik ditampilkan, sebagai narasi tentang kejayaan kerajaan dan para raja. Dalam hal ini, bangsawan Bali Utara cerdas dalam menciptakan gaya berbusana tersendiri dengan menunjukkan cita rasa yang khas sehingga busana yang dikenakan mudah dikenali sebagai salah satu identitas bangsawan Bali Utara.

Kedatangan bangsa Barat ke Bali sejak abad ke 16 membawa perubahan dalam gaya hidup bangsawan, termasuk gaya busana. Gaya fashion bangsawan Bali Utara merupakan bentuk kolaborasi sistem busana lokal dengan gaya bangsa asing khususnya fashion Barat. Oleh karena itu, gaya berbusana bangsawan Bali Utara memperlihatkan karakter dan gaya tersendiri yang unik. Dari karakteristik busana bangsawan Bali Utara terlihat adanya hegemoni fashion Barat. Kajian ini menjelaskan sejarah kerajaan di Bali Utara, kedatangan bangsa Barat, dan modus hegemoni fashion Barat pada busana yang dikenakan bangsawan di Bali Utara.

Puri-puri Besar di Bali Utara

Dari delapan kerajaan besar (Astanegara: Badung, Bangli, Buleleng, Gianyar, Jembrana, Karangasem, Klungkung, dan Tabanan) di Bali, dua kerajaan besar terdapat di 
bagian utara Bali, yakni Kerajaan Karangasem dan Kerajaan Buleleng. Dua kerajaan besar tersebut memiliki kedekatan secara historis maupun kekerabatan. Setelah Belanda menguasai Bali, Kerajaan Buleleng yang berpusat di Singaraja menginduk pada Kerajaan Karangasem di Amlapura. Adik raja Karangasem diangkat sebagai penguasa di Buleleng. Puri Singaraja adalah puri ke tiga yang dibangun, sejak Kerajaan Buleleng berdiri pada 1604 kemudian Singaraja dipilih oleh Belanda menjadi pintu masuk untuk menguasai Bali secara keseluruhan. (Girindrawardani, 2014).

Sejarah Puri Karangasem sendiri bermula dari figur sentral bernama Gusti Anglurah Batan Jeruk yakni patih dari Kerajaan Gelgel Klungkung. Setelah gagal mengkudeta raja Dalem Bengkung, Gusti Anglurah Batan Jeruk membanguan kekuasaanya sendiri di Karangasem (Vickers dkk, 2014). Namun demikian, I Gusti Anglurah Ketut Karang lah yang membangun istana (puri) pertama di Karangasem pada 1661 dan menjadi raja resmi pertama di Kerajaan Karangasem. Sedangkan sejarah Kerajaan Buleleng dimulai sejak pertengahan abad ke-17 Masehi. Pendiri Kerajaan Buleleng bernama I Gusti Anglurah Panji Sakti dari Wangsa Kepakisan. Kerajaan Karangasem yang bertetanggaan di sebelah Timur berkembang pesat hingga berhasil menganeksasi kerajaan-kerajaan di Lombok dan Buleleng pada 1780 pada era kepimimpinan I Gusti Ngurah Jelantik (Hanna, 2004). Oleh karena itu, ada ikatan persaudaraan dan budaya yang kuat di antara kerajaankerajaan tersebut. Selanjutnya ciri khas Puri Karangasem yang ke Barat-baratan juga diadopsi oleh Puri Buleleng. Ada banyak persamaan kebiasaan termasuk dalam berbusana.

Interaksi Puri-puri Bali Utara dengan Bangsa Barat Kedatangan armada kapal Barat, khususnya Belanda di Bali dimulai pada 1597 oleh Cornelis de Houtman. Kedatangan de Houtman merupakan tindakan penjajakkan atau penjelajahan awal di Bali yang kemudian ditindak lanjuti pada tahun 1601 oleh Cornelis van Heemskerck. Kedatangan awal bangsa Belanda ini masih bersifat damai dan diterima baik oleh masyarakat. Akan tetapi, selanjutnya Barat (Belanda) menggunakan jalur kekerasan untuk menguasai Bali. Istana atau puri dibumihanguskan dan keluarga bangsawan diasingkan ke kota Jagaraga,15 kilometer dari Singaraja. Perlawanan dipadamkan dengan mengangkat I Gusti Ngurah Ketut Djlantik menjadi Raja Buleleng pada 1858. Raja termuda dan yang terdidik ini juga kemudian dibuang ke Padang Sumatera Barat pada 1872 (Hanna, 2004).

Puri Karangasem atau Karang Samadi merupakan satu dari beberapa kerajaan terbesar di Bali yang terletak di Bali Utara. Seperti yang dinyatakan dalam dokumen bersejarah Sading C yang ditemukan di Geria Mandara, Munggu, Badung. Dokumen tersebut mengungkapkan bahwa Gunung Lempuyang di sebelah tenggara Amlapura,

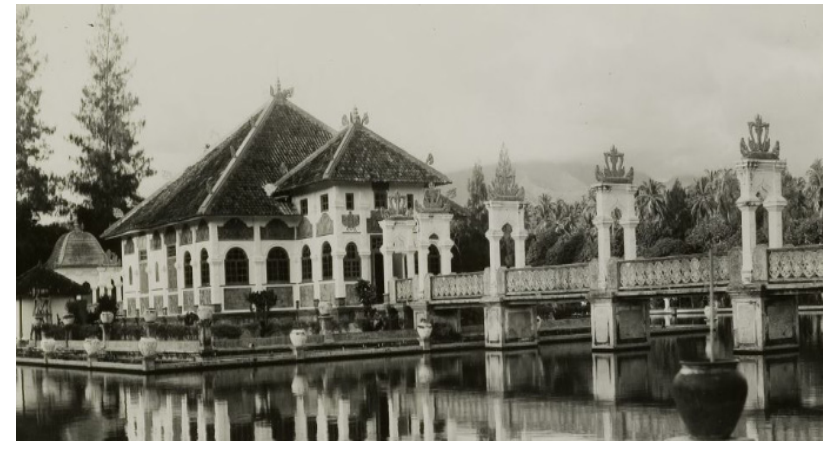

Gambar 1. Pengaruh Barat pada ornamen bermotif mahkota pada bantala dan murdha bangunan

di Taman Ujung Karangasem.

(Sumber: Girindrawardani, The Last Rajah of Karangasem, 2014)

awalnya bernama Adri Karang, yang artinya Gunung Karang. Kerajaan ini sebelumnya berada dalam kekuasaan Gelgel sampai abad ke-17. Raja pertama Karangasem adalah Batanjeruk yang diberikan hak untuk memimpin kerajaannya oleh ayahanda I Dewa Karangamla, raja Gelgel (Girindrawardani, 2014).

Kerajaan Karangasem berkembang dengan pesat. Kerajaan ini memperluas wilayahnya sampai ke Lombok, Sumbawa, dan Blambangan ketika Raja Dalem Waturenggong berkuasa pada abad ke-15. Kerajaan Karangasem disegani oleh kerajaan lainnya di Bali. Puncak kejayaan Karangasem yakni pada 1661 saat dipimpin oleh I Gusti Anglurah Ketut Karang. Karangasem berkembang dalam budaya dan seni. Kebudayaan berkembang diperkaya oleh budaya bangsa asing dan kerajaan sahabat, seperti: Klungkung, Buleleng, Cakranegara, Cina, dan Belanda melalui perdagangan dan interaksi sosial.

Sebenarnya, kontak pertama Bali dengan Barat terjadi pada tahun 1512, yakni dengan bangsa Portugis di daerah pantai utara. Spanyol dan Portugis berhasil memetakan Bali pada tahun yang sama. Sir Francis Drake dari Inggris mengunjungi Bali di tahun 1596. Sementara itu kapalkapal Belanda datang ke Bali tahun 1597 di daerah pantai selatan, dengan menggunakan rute pelayaran bangsa Portugis sebelumnya. Pada tahun 1601 kapal Belanda mendapatkan ijin berdagang. Intervensi Belanda pada 1894 berbuah kolonisasi penuh atas Bali dan Lombok. Setelah itu Belanda melantik Gusti Gede Jelantik yang ditunjuk sebagai perwakilan pemerintah Belanda pada 1894. Gusti Gede Jelantik memerintah hingga 1902.

Sebelum orang Barat tiba, orang Bali telah berdagang dengan orang asing yang datang dari berbagai belahan dunia. Pedagang India datang kira-kira pada abad 7. Mereka menjual keramik, kain, dan barang-barang lainnya. Yang menjadi catatan penting adalah masuknya ajaran Hindu ke Bali (Lansing, 1983). Bangsa Cina datang kemudian. Umumnya mereka melakukan barter porselen, 


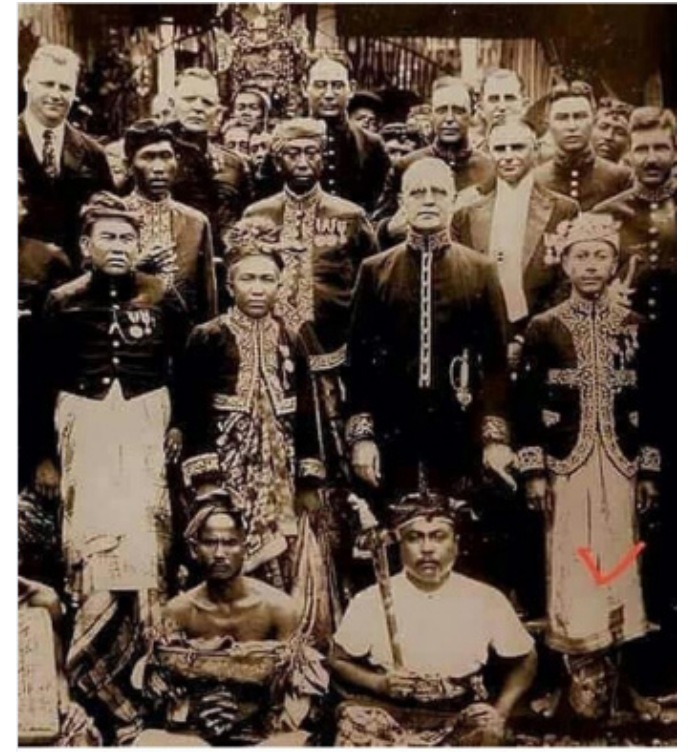

Gambar 2. Puri-puri di Bali Utara menjalin hubungan dengan bangsa Barat.

(Sumber: Tropenmuseum )

pedang, dan barang lainnya dengan kain katun Bali. Saat itu Bali dikenal sebagai tempat singgah bagi kapal-kapal dari berbagai penjuru untuk memperoleh air tawar dan makanan. Mereka juga berkesempatan untuk membeli ternak dan budak dari Bali.

Pertanian menjadi komoditas utama dari Bali. Produksi beras mengalami surplus tetapi raja melarang ekspor beras. Produk agrikultur lainnya, seperti: kelapa, jeruk, lemon, kacang, dan sebagainya berlimpah untuk mencukupi kebutuhan sehari-hari masyarakat dan kebutuhan untuk festival budaya. Bali juga mengekspor tekstil katun tetapi mengimpor besi, tembaga, dan emas. Tidak dimengerti alasannya, Raja dengan pertimbangan tertentu melarang pertambangan emas di Bali (Lach \& Van Kley,1998:13581359).

Perdagangan dari luar ke dalam Bali juga bermakna hubungan orang Bali dengan bangsa asing. Hal ini menyebabkan perubahan sosiokultural dalam masyarakat Bali. Pedagang dari India, Cina, Arab, Jawa, Bugis, dan tetangga Timur Bali membawa masuk tidak hanya barangbarang tetapi juga kebiasaan (Hanna, 2016:16). Selama mereka di Bali, tuan rumah berlaku sangat ramah bagi pendatang asing. Hanna (2016:28) bahkan menyebutkan bahwa Dewa Agung menyediakan rumah dan isteri bagi tamu asing dari Portugis.

Orang Bali percaya apa yang datang dari luar merupakan bagian dari alam semesta yang identik dengan manusia. Dengan dasar kepercayaan inilah orang Bali menyambut orang asing sebagai tamu dengan ramah (Seraya et all,1995:10). Perihal orang Barat, menurut Picard (2006:198), orang Bali cenderung menganggap ide-ide baru dari Barat dianggap sebagai "modern" dan layak dicontoh. Di dalam Istana Karangasem, ide-ide Barat terefleksi dalam berbagai aspek gaya hidup, seperti cara berbusana raja yang kemudian diikuti oleh seluruh keluarga bangsawan.

Bangsawan Bali Utara Mengecap Pendidikan Barat Salah satu misi bangsa-bangsa Barat dalam propaganda Gold, Glory, Gospel (3G) adalah sivilisasi negara jajahan, yang praktiknya dijalankan oleh institusi pendidikan dan agama (Wardhani, 2016). Demikian juga Belanda yang telah membuka sekolah rendah yang pertama di Bali, yakni di Singaraja (1875) yang dikenal dengan nama Tweede Klasse School. Pada tahun 1913 dibuka sebuah sekolah dengan nama Erste Inlandsche School dan kemudian disusul dengan sebuah sekolah Belanda dengan nama Hollands Inlandshe School (HIS) yang muridnya kebanyakan berasal dari anak-anak bangsawan dan golongan kaya. Pendidikan merupakan wadah membentuk pola pikir termasuk gaya hidup bangsawan Bali Utara.

Salah satu gaya hidup yang berubah adalah kesadaran berpenampilan baik dan menarik (fashionable). Kesadaran fashion umumnya hanya muncul pada orang-orang terdidik. Sekolah-sekolah Barat merupakan wahana penularan budaya Barat yang efektif. Murid-murid yang dididik secara langsung dan tidak langsung meniru gaya hidup dan cara berpakaian orang-orang Barat sebagai agen pendidikan. Tanpa disadari siswa-siswa di sekolah membentuk citra diri sendiri. Berbusana ala Barat tidak saja menjadi keharusan etika di sekolah, juga sebagai penanda bagi kelompok intelektual dan bangsawan yang pertama sekali mempunyak hak istimewa untuk bersekolah.

Puri Karangasem memiliki hubungan yang baik dengan pemerintah Belanda. Hal ini merupakan keputusan politik berkaitan dengan kebijakan luar negeri. Dua raja Karangasem, I Goesti Gde Djelantik dan keponakannya I Goesti Bagoes Djelantik percaya bahwa peradaban Barat akan membawa kemajuan bagi Kerajaan Karangasem (Wijaya, 2018:26). Oleh karena itu, Kerajaan Karangasem menjadi lebih kebarat-baratan dibanding kerajaaan lainnya di Bali. Bahkan arsitektur Istana Karangasem adalah wujud dedikasi terhadap pemerintah Barat, sehingga diberi nama kota-kota di Eropa, seperti; Amsterdam dan London. Akibat kemajuan ini, pada tahun 1936 Karangasem disebut-sebut sebagai kota yang paling banyak kehilangan karakter kebaliannya (Djelantik, 2018:27). Pengaruh Barat dalam Puri Karangasem dibuktikan dalam berbagai cara hidup dalam puri, termasuk dalam pendidikan dan busana. Gaya hidup kebarat-baratan di dalam Puri Karangasem adalah hasil dari keputusan politik untuk bekerjasama dengan Barat, khususnya Belanda. Sebelumnya, raja Karangasem telah berjanji untuk tunduk pada pemerintah Belanda. Secara politik Kerajaan Karangasem telah menjadi bagian dari wilayah administratif Belanda pada 1896 (Wijaya, 2018:37). Raja pun ditunjuk menjadi representasi pemerintah Belanda (stadehouder). Serta 


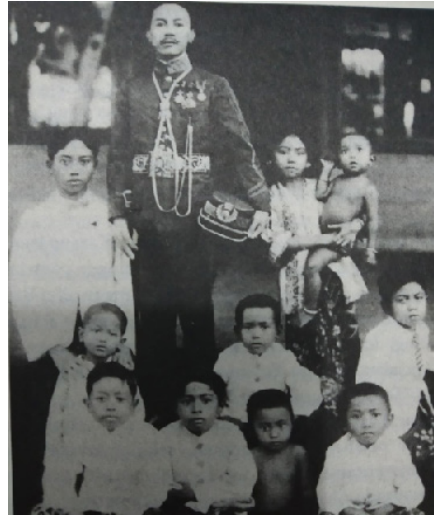

Gambar 3. Potret Keluarga 1928. Raja menggunakan seragam stadehouder; para pangeran menggunakan kemeja, dasi, dan celana; putri raja menggunakan baju dan wastra.

(Sumber: Wijaya, Bening Embun, 2018)

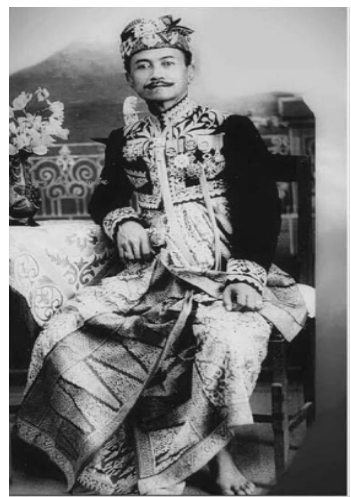

Gambar 5. Raja Karangasem; Anak Agung Anglurah Ketut Karangasem dengan busana kebesarannya. Elemen Barat terlihat pada baju dan aksesoris, seperti: medali, pin, dan jam kantong yang berantai. Pada jaket terlihat aksesoris dan motif daun laurel khas bangsawan Barat yang menghiasi kerah jaket.

(Sumber: Wijaya, Bening Embun, 2018)

merta, etika berbusana dari Barat menjadi bagian dari gaya hidup Puri Karangasem.

"We were dressed up in our new white "western" clothes for our visit to the Dutch Headmaster of the H.I.S. (Holland Inlandse School). We wore short pants and closed jackets with long sleeves and upright collar, all stiffened with starch and neatly ironed. At the front of the collar downwards we had a row of golden buttons which were actually American half-dollar coins provided with a metal loop at the backside. These loops were inserted through small holes at the rim of the jacket corresponding with the buttonholes at the opposite side. Safety pins, spiral metal rings, or just a sturdy cotton string held the buttons in place. The stiff collar was held closed by two small golden knobs with a flat base at the inside. We wore barefooted, and we wore no hats...Father had put on his official white Stedehouder's uniform, with several medals on his breast." (Djelantik,1997: 32).

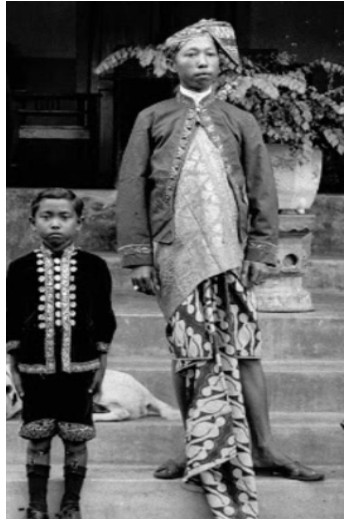

Gambar 4. Seorang bangsawan Buleleng dengan busana pria jas lengan panjang dengan model kancing di atas, busana anak dengan jas beludru dan celana panjang merupakan fashion Barat yang diterima di lingkungan puri di Bali Utara.

(Sumber: Tropenmuseum)

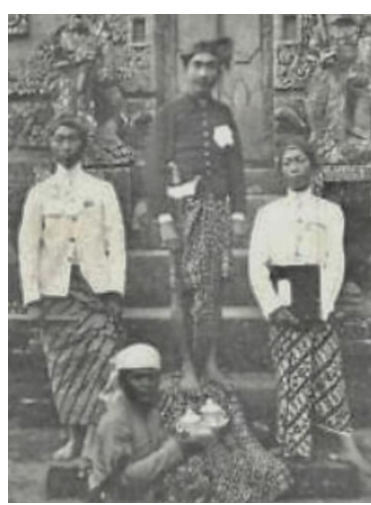

Gambar 6. Busana pria bangsawan Buleleng. Baju lengan panjang dengan aksesoris baju yang merupakan warisan fashion Barat. (Sumber: Tropenmuseum.)

Westernisasi di Puri Karangasem sangat terlihat jelas, khususnya di Puri Kanginan. Bangsawan bersekolah di sekolah Barat, mengadopsi selera dan prilaku Barat. Penampilan mereka kemudian bertranformasi, dari gaya tradisional menjadi gaya ke barat-baratan dengan mengenakan kemeja/baju, dasi, topi, celana, dan sepatu. Di Singaraja hubungan Barat dan Timur berkembang melalui interaksi sosial pada aktivitas perdagangan dan pendidikan. Singaraja menjadi pelopor pendidikan Barat di Bali dan menjelma sebagai kota pendidikan. Dengan cara ini Puri Buleleng kemudian mengikuti langkah Puri Karangasem menerima pengaruh Barat dalam hal berbusana.

Hegemoni Fashion Barat di Puri Bali Utara

Hegemoni merupakan bentuk supremasi satu kelompok atau lebih atas kelompok lainnya dalam setiap hubungan sosial. Gramsci (dalam Sugiono, 1999) menyebut karakter hegemoni dengan istilah "pengaruh kultural". Menurut Gramci, agar yang dikuasai mematuhi penguasa, yang dikuasai tidak saja harus menginternalisasi nilai-nilai serta norma penguasa, lebih dari itu mereka juga harus 

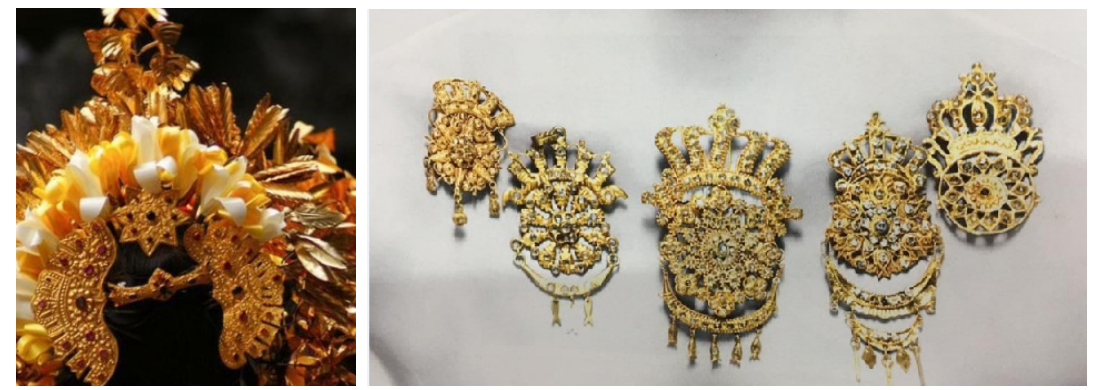

Gambar 7. Cucuk atau tusuk konde dengan motif mahkota adalah bagian dari hiasan kepala perempuan Bali yang disebut pusung. Bros dengan motif mahkota merupakan motif yang banyak dipakai sebagai akseoris oleh wanita puri termasuk Puri Karangasem dan Buleleng. (Sumber: Harper Bazar Magazine, 2011)

memberi persetujuan atas subordinasi mereka. Inilah yang dimaksud Gramci dengan "hegemoni" atau menguasai dengan "kepemimpinan moral dan intelektual" secara konsensual.

Gaya hidup bangsawan Bali Utara yang ke barat-baratan merupakan hasil hegemoni kultural. Salah satu gaya hidup ke Barat-baratan yang dianut bangsawan Bali Utara adalah fashion. Sebelumnya bangsawan mengenakan busana tradisional dengan kain-kain persegi panjang, seperti: songket, endek, batik, dan prada yang menjadi kode busana di puri. Penggunaan tekstil tradisional merupakan kebiasaan asli dalam puri. Hal ini didukung oleh kemampuan leluhur orang Bali yang ahli dalam menenun (Schaublin, 1997:7). Semangat kebaharuan ini ditandai dengan perubahan berbusana.

"Memang sulit dipungkiri kalau kehidupan warga Puri Karangasem selalu diwarnai dengan hal-hal yang" berbau "modern" dan mewah. Bahkan hanya bentuk bangunan, gaya hidup orang-orang Barat yang serba modern nyatanya tak luput dari sorot mata para penerus dinasti istana Karangasem.Tanpa segan-segan mereka menirunya." (Wijaya,2018:31)

Bagaimana bangsawan Karangasem sangat selektif dalam berbusana merupakan sebuah fenomena budaya. Dalam hal ini Geertz (1973:89) menjelaskan budaya sebagai " $a$ system of inherited conceptions expressed in symbolic forms by means of which men communicate, perpetuate, and develop their knowledge about and attitudes toward life". Demikian bangsawan Karangasem menggunakan busana dan pelengkapannya untuk mengkomunikasikan latar belakang sosial-kultural mereka. Walaupun budaya Barat bersifat invasif, budaya tersebut logis dan modern. Oleh karena itu, elit Puri Karangasem tidak ragu untuk menganutnya.

Satu hal yang paling penting dibawa oleh orang Barat adalah kesadaran akan waktu. Kesadaran waktu merupakan hegemoni Barat terhadap kepercayaan tradisional tentang dimensi waktu. Tanpa kesadaran waktu, Covarrubias (1973) pernah menyatakan betapa panjangnya waktu berjalan bagi penduduk asli Bali yang secara tradisional menjalankan waktunya. Oleh karena itu, raja Karangasem, Goesti Bagoes Djelantik sangat menyukai jam dan saat berbusana menggunakan jam kantong yang mahal (Wijaya, 2018;32).

Pengaruh fashion Barat pada busana bangsawan Karangasem dapat dikatakan sangat terlihat jelas. Bukti dapat ditemukan pada busana pria, khususnya dalam gaya, material, dan perlengkapan busana. Secara tradisional busana bangsawan pria Karangasem terdiri atas: baju, kamen, saput, dan perlengkapan busana pria, seperti: destar, keris, cincin, dan gelang. Kemudian dengan perubahan gaya Barat dilengkapi dengan elemen modern, seperti: medali, pin, dan jam kantong .

Para pria bangsawan biasanya memakai baju pekongan, yakni baju pendek dengan lengan panjang. Baju khusus pria bangsawan ini memiliki karakter unik, yakni pada bagian bawahnya lebih pendek. Pada bagian ketiak baju terdapat lengkungan ke arah bagian belakang sebagai tempat untuk menyematkan keris. Jaket pendek seperti ini juga dipakai oleh matador Spanyol yang disebut traje de luces sejak abad ke18.

Pada acara khusus, seperti upacara adat, pria bangsawan mengenakan baju pekongan dengan wastra lanang. Baju raja dihiasi dengan aksesoris, seperti: medali, pin, dan jam kantong. Pada kesempatan yang lain, misalnya ketika menyambut tamu negara Barat, raja akan mengenakan baju yang desainnya lebih sederhana. Biasanya desain baju dibawa ke Jawa dan dikerjakan oleh penjahit di Solo. Pada masa itu, belum ada penjahit di Bali.

Elemen Barat ditemukan juga pada bahan baku tekstil, kancing, dan benang. Baju terbuat dari kain yang diimport dari negara Barat, seperti: beludru, wool, katun dan sebagainya. Kerah baju dihiasi dengan pola dedaunan yang mirip dengan daun laurel dari Yunani. Selain itu, motif prada Belanda yang biasa ditemukan pada motif ragam hias songket, endek, dan kain prada juga merupakan pengaruh Barat. 


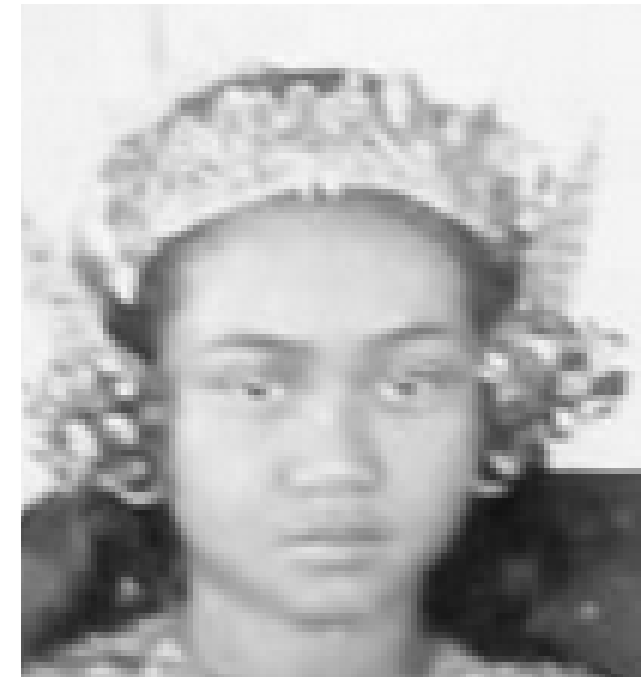

Gambar 8. Hiasan blengker pada kepala wanita bangsawan terinspirasi dari mahkota atau tiara dari Eropa.

(Sumber: Tropenmuseum)

Tradisi berdandan dengan busana indah dalam puri menjadi sebuah norma. Tradisi ini terjaga, namun demikian berubah dari waktu ke waktu. Wanita bangsawan Bali Utara juga memiliki kebiasan berdandan seperti halnya bangsawan pria. Mereka suka mengenakan busana yang indah dan aksesoris yang mahal. Ketika menghadiri sebuah upacara adat atau ritual keagamaan, wanita bangsawan Karangasem mengenakan baju beludru bersulam emas yang disebut baju kastim. Baju ini dihiasi dengan bros emas bermata berlian dengan pola buketan bunga yang juga merupakan pengaruh Eropa. Pada acara yang lebih kecil, wanita bangsawan hanya menggunakan kebaya berbahan katun (kain cita) dan wastra istri.

Kebaya telah dipakai oleh wanita di Bali Utara selama se-abad. Kebaya adalah busana Melayu yang dibawa oleh Belanda. Pada awalnya para wanita Bali dipaksa dengan sebuah dekrit resmi yang berbunyi: "to protect the morals of the Dutch soldiers" (Covarrubias, 1973: 93). Busana ini diadopsi oleh anggota keluarga kerajaan kemudian dipaksakan kepada masyarakat luas. Kaum wanita di Buleleng menjadi wanita pertama yang mengenakan kebaya di Bali. Bahan untuk kebaya umumnya terbuat dari sutera, brokat, dan beludru yang diimport dari Barat, namun kaum wanita puri cenderung memilih beludru.

Pemaksaan moral Barat pada wanita Bali jelas merupakan cara bekerjanya (modus operandi) hegemoni fashion Barat terhadap tata busana tradisional Bali. Menurut Hardiman (2012:37), kolonialisme tidak saja bertujuan kepentingan ekonomi tetapi juga dalam rangka peradaban (domestifikasi) dengan standar-standar Eropa yang dianggap universal. Orang-orang jajahan harus berdandan seperti orang Eropa, berbicara dalam bahasa Eropa, dan mengikuti adat Eropa atau singkatnya menjadi 'manusia'. Penggunaan perhiasan ada hubungan dengan pernyataan status sosial. Jumlah perhiasan, desain dan motif, serta

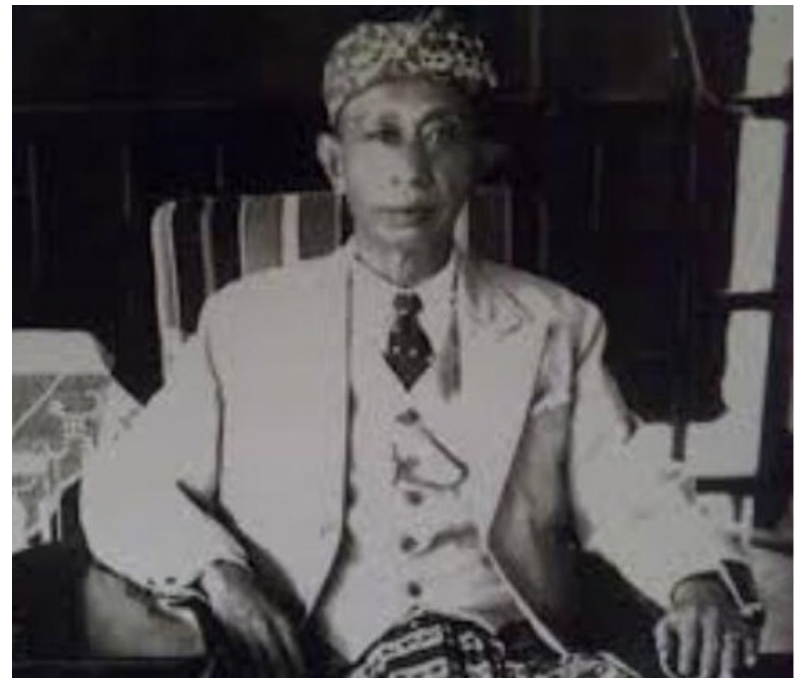

Gambar 9. Bangsawan Buleleng mengenakan jas, rompi, dan dasi merupakan etiket berbusana pria modern ala Barat.

(Sumber: Tropenmuseum)

kualitas karat perhiasan akan menjelaskan hirarki seseorang dalam istana. Mahkota tidak saja sebagai hiasan kepala tetapi menjadi simbol kebesaran. Pada abad ke 20 mahkota Eropa menjadi motif hias yang umum pada perhiasan di Asia Tenggara termasuk Jawa dan Bali (Richter, 2000). Motif mahkota dan singa yang berasal dari Barat banyak digunakan dalam tekstil, aksesoris, dan kerajinan di Bali.

Permaisuri dan para putri di puri berdandan dengan mahkota khas Bali yang disebut pusung pada acaraacara besar. Pusung merupakan rangkaian sanggul dan sejumlah aksesoris dan bunga-bungaan. Pada pusung yang digunakan wanita bangsawan Karangasem terdapat blengker pada bagian depan. Blengker merupakan aksesoris emas yang berhiaskan permata. Inspirasi blengker berasal dari mahkota atau tiara yang dipakai oleh ratu dan putriputri Eropa.

Barat juga memperkenalkan jaket, dasi, topi, sepatu, sandal, dan perlengkapan busana lainnya yang memperkaya fashion tradisional. Bangsawan Karangasem mulai mengenakan sandal dan sepatu saat Belanda berkuasa di Bali. Sebelumnya, masyarakat Bali tradisional tidak mengenal alas kaki. Para bangsawan terbiasa bertelanjang kaki bahkan saat mengenakan busana kebesaran yang mewah.

Dampak terbesar budaya Barat bagi Bali adalah teknologi. Orang Barat memperkenalkan busana yang dijahit yang terbuat dari kain-kain buatan pabrik di mana sebelumnya mereka hanya menggunakan kain-kain tradisional berbentuk persegi panjang (Vickers, 2012). Penggunaan busana yang dijahit merupakan perubahan besar dalam sistem fashion tradisional Bali. Busana juga merupakan simbol gerakan egalitarian yang kemudian terjadi dalam struktur sosiokultural di Bali. 


\section{SIMPULAN}

Hegemoni fashion Barat terhadap busana bangsawan Bali Utara 1800-1940 tidak terjadi secara tiba-tiba melainkan berlangsung secara perlahan dimulai dengan interaksi antara pendatang, yakni para pedagang Barat, dengan penduduk lokal Bali di abad ke 16, tepatnya sejak kedatangan bangsa Portungis pertama kali. Dari hanya sekedar aktivitas berdagang, interaksi manusia menghasilkan pertukaran budaya. Pertukaran budaya yang awalnya terjadi secara alamiah secara perlahan mengubah budaya Bali asli. Salah satu yang terlihat adalah gaya hidup yang ditampilkan melalui cara berbusana. Gaya hidup juga dibentuk melalui pendidikan. Melalui pendidikan pulalah lingkungan istana atau kaum bangsawan mengadopsi budaya Barat termasuk fashion. Selain pendidikan yang bersifat hegemonik, pengaruh fashion Barat juga masuk melalui pemaksaan moral seperti pada baju kebaya.

Hegemoni fashion Barat pada busana bangsawan Bali Utara ditampilkan tidak saja dalam etiket berbusana seperti ke sekolah, tapi juga terlihat dari struktur busana. Kaum pria bangsawan mulai menggunakan jaket yang sama digunakan oleh bangsawan Eropa. Demikian pula dengan aksesoris, seperti: medali, pin, dan jam kantong yang merupakan aksesoris khas Barat. Kaum bangsawan wanita menyukai pakaian-pakain indah yang awalnya diperkenalkan oleh bangsa Barat. Mereka juga berhias dengan mahkota dan bros yang terinspirasi oleh putri-putri di Eropa. Hegemoni Barat pada fashion puri sangat kuat dalam material, motif, dan desain.

\section{DAFTAR RUJUKAN}

Arumsari, Arini, Agus Sachari, \& Andryanto Rikrik Kusmara. (2019). The influence of traditional values on the development of fashion in Bali. The Research Journal of the Costume Culture, Vol.27 No.3 pp.264-273. Doctorate Program of Visual Art and Design, Institut Teknologi Bandung, Indonesia.

Billah, M.M. (1996), Good Gorvenance dan Kontrol Sosial Realitas dan Prospek, Prisma, 8 Agustus, p. 43.

Covarrubias, Miguel. (1973), Island of Bali. Periplus Editions, Singapore.

Djelantik, A.A.M. (1997). The Birthmark-Memoirs of a Balinese Prince. Periplus Editions, Singapore.

Geertz, Clifford. (1973., The Interpretation of Cultures, Selected Essays. Basic. New York.

Girindrawardani. A.A.A.Dewi, Adrian Vickers, \& Rodney Holt, (2014), The Last Rajah of Karangasem, Saritaksu, Denpasar.
Hanna, Willard A.(2004), Bali Chronicles, Periplus, Singapore.

$$
\text { (2016), A Brief History Of Bali: }
$$

Piracy, Slavery, Opium, and Guns: The Story of an Island Paradise, Tuttle Publications, Singapore.

Hardiman, F.Budi. (2012), Humanisme dan Sesudahnya, KPG (Kepustakaan Populer Gramedia), Jakarta

Jelantik, Ida Nyoman, et al. (2003), History of Puri Karangasem, Culture and Tourism Offices of Karangasem, Denpasar.

Lach, Donald F and Edwin J. Van Kley. (1998), Asia in the Making of Europe, Volume III: A Century of Advance. Book 3South East of Asia, University of Chicago Press, Chicago.

Langi, Kezia Clarissa, dan Park Shinmi (2017) "An Analysis of the Characteristics of Balinese Costume" dalam Journal of the Korean Society of Costume, Vol. 67, No. 4 (June 2017) pp. 38-57. Associate Professor, Dept. of Clothing \& Textiles, Andong National University.

Lansing, JS. (1983), The Indianization of Bali. Journal of South and Southeast Asian Studies 14(2).

Rowman \& Littlefield. (2020), Fashionable Traditions: Asian Handmade Textiles in Motion, (Ayami Nakatani, ed.), Lexington Books, New York.

Patria, Nezar dan Andi Arief. (2003), Antonio Gramsci Negara dan Hegemoni, Pustaka Pelajar, Yogyakarta.

Picard, Michael. (2006), Bali: Pariwisata Budaya dan Budaya Pariwisata, Kepustakaan Populer Gramedia, Jakarta.

Richter, Anne. (2000). The Jewelry of Southeast Asia, Thames and Hudson Ltd, London .

Schaublin, Brigitta Hauser, et al. (1997), Balinese Textiles, Peri Plus Edition, Singapore .

Seraya, I Made, dkk. (1995), Pengerajin Tradisional di Daerah Bali, Direktorat Jenderal Kebudayaan, Denpasar.

Soedibyo, BRA. Mooryati. (2003), Busana Keraton Surakarta Hadiningrat. Jakarta: PT Gramedia Widiasarana Indonesia.

Sugiono, Muhadi. (1999), Kritik Antonio Gramsci terhadap Pembangunan Dunia Ketiga, Pustaka Pelajar, Yogyakarta.

Taylor, Lou. (2002), The Study of Dress History, Manchester University Press, New York. 
Vickers, Adrian. (2012), Balinese Art: Paintings and Drawings of Bali 1800- 2010, Tuttle Publishing, Singapore.

(2014), The Last Rajah of Karangasem, Saritaksu, Denpasar.

Wardhani, Baiq L.S.W. (2016), Respon Poskolonial terhadap Intensifikasi Pendidikan Kolonial di Afrika, Universitas Airlangga, Surabaya.

Wijaya, Nyoman. (2018), Bening Embun: Perjalanan A.A.Made Djelantik, Pustaka Larasan, Denpasar . 